\title{
Business coaching: Implementation of digital marketing and addition of online channels in Indonesian MSME's F\&B business during the 2020 pandemic
}

\author{
A. Adawiyah \& H. Suhaimi \\ Faculty of Business and Economics, University Indonesia, DKI Jakarta, Indonesia
}

\begin{abstract}
This paper aims to assist MSMEs in Indonesia in marketing activity management during the COVID-19 pandemic by implementing certain strategies to increase their promotion. The data were collected using the business coaching method. In this study, qualitative research was used to map MSMEs' conditions and problems. Afterward, corrective actions were given to implement remedial solutions. It was found that the survival solutions that can be applied by the companies include creating online channels, adding new product variations, and managing Instagram accounts to support marketing activities. After the implementation of the solutions, it was shown that their sales increased significantly and it has helped the company to survive during the difficult times caused by the pandemic.
\end{abstract}

\section{INTRODUCTION}

Coffee shop business, a popular culinary business, comprises many MSMEs in Indonesia. SiCangkir Coffee, founded in 2017, is one of the MSMEs in the food and beverages sector that were operational during the COVID-19 pandemic. Many MSMEs, especially restaurants and cafés, encountered difficulties in running their business during the pandemic. Hence, understanding MSMEs' condition holistically is necessary to find the best solution for their challenges. In this case, several internal and external analyses are required to ensure the coffee shop businesses' survival. This study focuses on several important and feasible aspects necessary to improve SiCangkir Coffee's performance, namely, digital marketing, new product development, and online channel.

\section{LITERATURE REVIEW}

A theoretical basis is required to ensure the appropriate direction of the study. The theoretical bases of this study are as follows: Taiminen and Karjaluoto (2015) define digital marketing as a new marketing approach. The approach is not merely a traditional marketing channel supported by digital elements, but all marketing activities that utilize digital channels to promote products (Batra \& Keller, 2016). Instagram is a mobile social network for photo and video sharing. Ištvanic et al. (2017) estimated that Instagram has 700 million active users word widely. Furthermore, Ištvanic et al. (2017) suggest that Instagram is a great medium for advertising, as this platform can tell a story about a product or brand visually and interestingly. According to Cannon (2014), new product development consists of several stages: idea generation, idea screening, concept development and evaluation, business analysis, product development, test marketing, and commercialization. Walsh and Godfrey (2000) and Kim and Lennon (2012) define electronic commerce as shopping online via the internet. Unlike offline stores that allow consumers to interact directly with the seller, online stores facilitate communication between consumers and sellers through a technical interface. 


\section{RESEARCH METHOD}

This study is a descriptive qualitative research conducted through a business coaching method. The primary and secondary data were collected from interviews, observations, and SiCangkir Coffee's internal data. The business coaching will be implemented through four steps, namely, (1) internal and external analysis; (2) TOWS, gaps analysis, and Pareto analysis; (3) alternative solutions and decision making; and (4) implementation and monitoring.

\section{RESULTS AND DISCUSSIONS}

The result shows that the coffee shop challenges should be addressed by several solutions: opening online channels, adding new product variations, and managing online promotion via Instagram. In Instagram online promotion, the most important aspect is the images. The posts should be bright, interactive, personal, and simple, while the layout needs to look professional. The findings show that the attempt to improve SiCangkir Coffee's Instagram profile structure has shown promising results, proven by increased engagement on the business's Instagram profile.
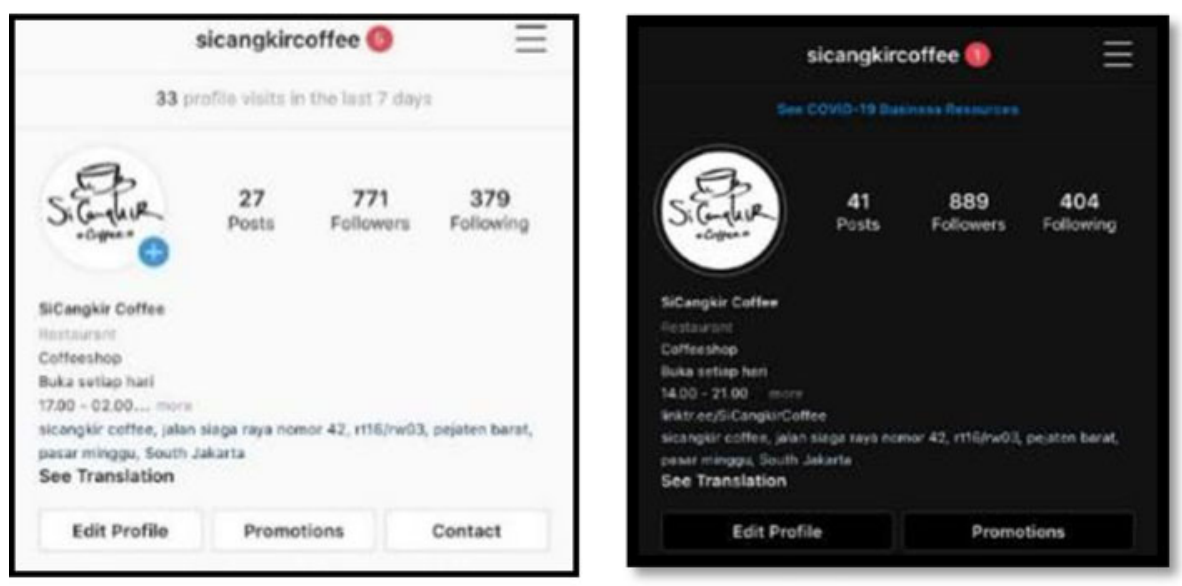

Figure 1. Comparison between before and after instagram improvement from Instagram.com/SiCangkir Coffee.

SiCangkir Coffee will add 'one-liter bottle packaging' as a product variation. According to Crawford and Benedetto (2015), this one-liter bottle packaging product addition can be categorized as new-to-the-firm products or new product lines. To complete the gap from the previous analysis which stated that MSMEs needed to add an online channel in order to keep it operational during a pandemic, the solution offered was to register MSMEs as a GoFood partner.

\section{CONCLUSION}

MSMEs must implement the right strategy to survive and operate optimally during the COVID-19 pandemic. The implementation results demonstrated that opening online channels, adding product variations, and managing online promotions can increase MSMEs' sales and keep them operational during the COVID-19 pandemic. 


\section{REFERENCES}

Ištvanic, M., Milic, D. C., \& Krpic, Z. (2017). Digital Marketing in the Business Environment. Digital Marketing in the Business Environment. Retrieved June 9, 2018.

HM Taiminen, H Karjaluoto (2015). The usage of digital marketing channels in SMEs. Journal of Small Business and Enterprise Development

J Walsh, S Godfrey (2000). The Internet: a new era in customer service. European Management Journal. Elsevier

Kim, J. H., \& Lennon, S. (2012). Music and amount of information: do they matter in an online apparel setting?. The International Review of Retail, Distribution and Consumer Research, 22(1), 55-82. 